
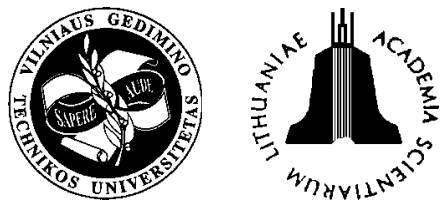

ISSN 1648-4142 TRANSPORT

http:/www.vtu.lt/english/editions

\title{
THE QUALITY OF MOTOR CARS AND ITS VARIATION IN TIME
}

\author{
Valentinas Mickūnaitis \\ Dept of Automobile Transport, Vilnius Gediminas Technical University, \\ J. Basanavičiaus g. 28, LT-03224 Vilnius-9, Lithuania.E-mail:tiauto@ti.vtu.lt
}

Received 2003-03-12; accepted 2004-04-15

\begin{abstract}
The paper considers the quality of motor cars and its changes during the vehicle service life. The process is analysed in terms of the theory of reliability. The emphasis is placed on the analysis of the work without breakdown and such issues as probabilities of breakdowns and breakdown-free operation, breakdown frequency, intensity and the average time of the vehicle run till failure.

Based on the statistical data breakdown probabilities of the particular systems, mechanisms and units, depending
\end{abstract} on the service life of a vehicle are determined.

Keywords: quality of motor cars, reliability, probabilities of breakdown and breakdown-free operation, frequency and intensity of breakdowns.

\section{Introduction}

The performance of motor cars depends on many factors. The first one is the quality of technical and technological documentation of maintenance and repair. The second factor is the quality of technological equipment. The third factor is the quality of raw materials used in car manufacture. The fourth and the main factor is the quality of work of executors including not only designers and manufacturers, but users as well. New laws and directives are more stringent with respect to car performance [1-3].

During the operation cars deteriorate, causing the change of their technical characteristics, which may lead to breakdowns. In addition to the above failures caused by long service life, some accidental breakdowns may occur due to manufacturing defects, overload, poor maintenance, bad weather, etc. [4-6].

The analysis of the changes in the operational state of a car will enable us to determine the reliability of particular systems, units and mechanisms.

\section{Major reliability criteria}

The reliability of motor cars and their components may be determined according to the following characteristics: work without breakdowns, longevity, repairability and durability. Various reliability criteria are used to define each of the above characteristics.

The moment of breakdown appearance as well as duration of the breakdown removal are random quantities, so the reliability indications will be estimated by the help of methods of probability theory and mathematical statistics.

The breakdown - free operation of motor car parts can be expressed by the following equation:

$$
P=P(t, T, S, V, F),
$$

here $P$-breakdown - free operation; $t$ - time in which the calculation of breakdown - free operation is performed; $T$ - length of the working time to the first fault of the given part; $S$-load character; $V$-character of load variation in time; $F$ - level of car workability support.

In many cases $S, V$ and $F$ are independent variables and they can be converted to constants. In such case breakdown - free operation will depend on the working time only:

$$
P=P(t, T) \text {. }
$$

We are primarily concerned with the criteria related to breakdown-free operation. These are probability of breakdown-free operation $P(t)$, breakdown frequency $f(t)$, breakdown intensity $\lambda(t)$ and average time of operation before a breakdown $t$ occurs [5].

The probability of breakdown-free operation may be described by the following relationship:

$$
P(t)=\int_{0}^{\infty} f(t) d t=1-F(t),
$$

here $f(t)$ - breakdown density; $F(t)$ - breakdown probability. 
For given statistical data on the breakdowns the probability of breakdown-free operation can be found from the following equation:

$$
P *(t)=\frac{N_{0}-n(t)}{N_{0}},
$$

here $P *(t)$-statistical evaluation of the breakdownfree operation probability; $N_{0}$ - number of parts at the beginning of testing; $n(t)$ - the number of broken parts in time $t$.

In practice it is more suitable to rely on breakdown probability $F(t)$ which is a probability of at least one breakdown during a certain period of operation:

$$
F *(t)=\frac{n(t)}{N_{0}}
$$

or to use breakdown frequency:

$$
f *(t)=\frac{n(\Delta t)}{N_{0} \Delta t},
$$

here $F^{*}(t)$ and $f^{*}(t)$-statistical breakdown probability and statistical breakdown frequency; $n(t)$ - the number of broken parts in time $t ; n(\Delta t)$ - the number of broken parts in time interval from $t-\frac{\Delta t}{2}$ to $t+\frac{\Delta t}{2} ; N_{0}$ - the number of parts at the beginning of testing.

Frequency of breakdowns or density of breakdown distribution is a relationship between the number of broken parts during the operational period and the time of operation and the initial number of parts when the broken parts are not replaced by new or repaired parts.

Breakdown intensity is conditional density of parts breakdown determined for a particular moment of time under the condition that no breakdown occurred till that time. A statistical expression of breakdown intensity is the number of broken parts per unit of time or an operational period with respect to one working part at the moment $t$ :

$$
\lambda *(t)=\frac{n(t+\Delta t)-n(t)}{N(t) \Delta t},
$$

here $n(t+\Delta t), n(t)-$ the number of broken parts at the moments $t+\Delta t$ and $t ; N(t)-$ the number of working parts at the moment $t$.

Breakdown intensity $\lambda(t)$ is a function of time or an operation period, therefore, it changes in time. Breakdown intensity may also be calculated from this formula:

$$
\lambda *(t)=\frac{n(\Delta t)}{N_{v i d} \Delta t},
$$

here $n(\Delta t)-$ the number of broken parts from $t-\frac{\Delta t}{2}$ until
$t+\frac{\Delta t}{2} ; \quad N_{v i d}=\frac{N_{i}+N_{i+1}}{2}-$ an average number of unbroken parts in a particular time interval;

$N_{i}$ - the number of unbroken parts at the beginning of time interval $\Delta t$;

$N_{i+1}$ - the number of unbroken parts at the end of time interval $\Delta t$.

The mean working time to breakdown is named as average working time to breakdown. The average working time to breakdown of a part can be calculated in accordance with the following formula:

$$
t_{\text {vid }}=\sum_{i=1}^{N_{0}} t_{i}
$$

here $t_{i}$ - the working time to breakdown of $i$-th not repairable part.

When the parts are wearing and getting obsolete, the intensity of motor cars breakdowns increases $[4,7]$.

\section{The analysis of breakdown intensity}

In Figs 1-4 the data of changes in the operational state of particular systems, units or mechanisms of all motor vehicles in Lithuanian car fleet depending on vehicle service life are given.

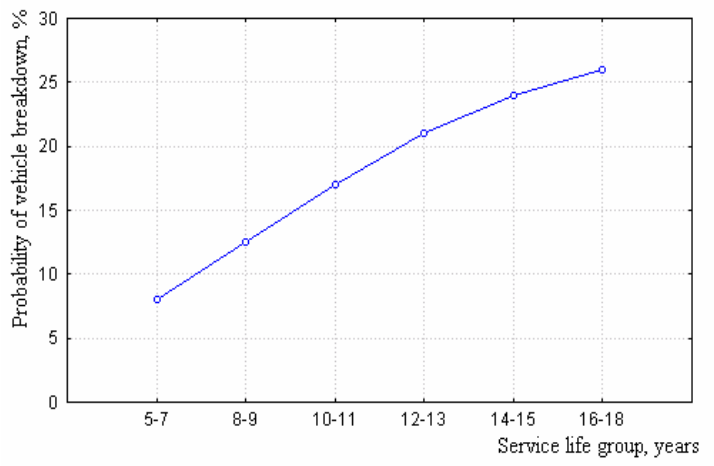

Fig 1. Breakdown probability of an engine and exhaust system parts depending on their service life

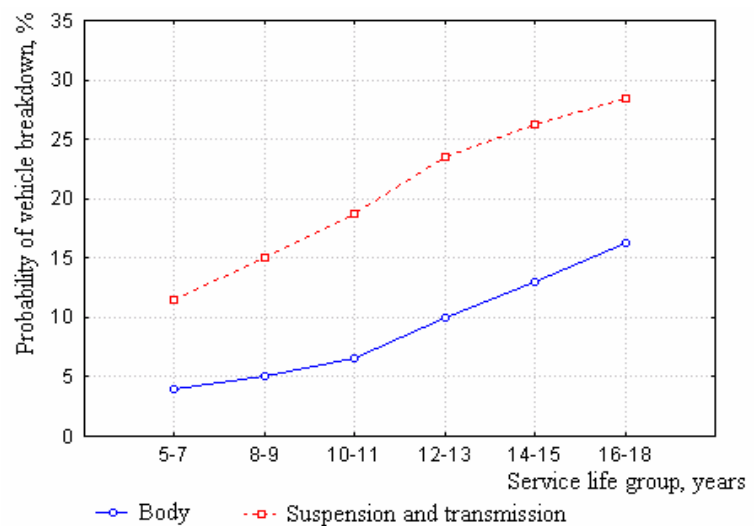

Fig 2. Breakdown probability of a car body and suspension depending on its service life 


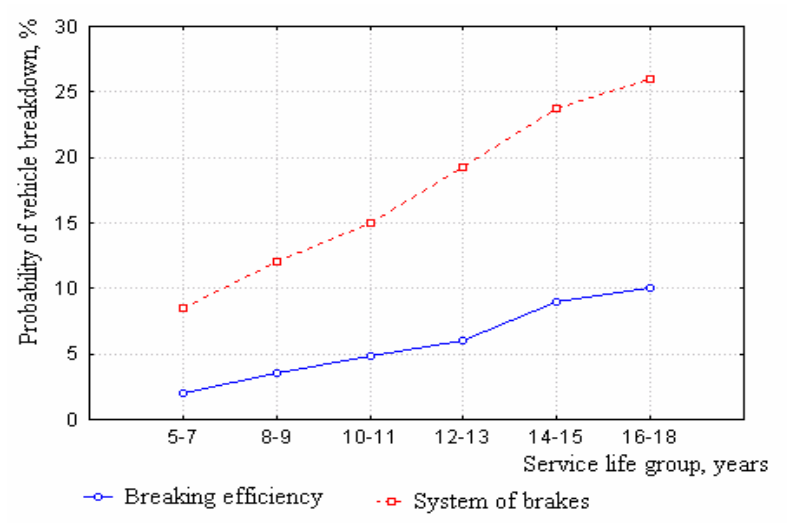

Fig 3. Probability of losing braking efficiency and brake system failure depending on their service life

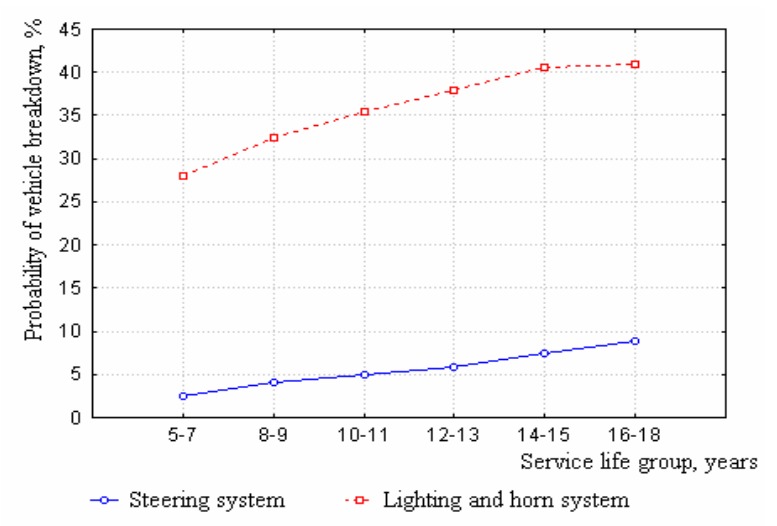

Fig 4. Breakdown probability of steering, lighting and horn system elements depending on their service life

As it is seen from the presented data, the age of motor cars has direct influence on their reliability. The minimal reliability is a characteristic feature of lighting and signaling system, as well as suspension and transmission. Such tendency is observed not only for aged cars, but also for cars of 5-7 years old.

\section{Conclusions}

1. Reliability of all systems, mechanisms and parts of motor cars decreases in time, while breakdown probability increases at a various rate.

2. Lighting and horn systems were found to be most unreliable: breakdown probability of cars of 5-7 years of service is about $28 \%$, while for cars of $16-18$ years of service it is over $40 \%$.

3. Service life of a motor car is the most important for its suspension and transmission: breakdown probability of cars belonging to a service life group of 5-7 years is about $12 \%$, while for those with 16-18 service life it reaches about $30 \%$.

\section{References}

1. Commission Directive 97/28/EC of 11 June 1997 adapting to technical Council Directive 76/756/EEC relating to the installation of lighting and light-signaling devices on motor vehicles and their trailers. Official Journal of the European Communities, No L171, 30.6, 1997, p. 1.

2. Commission Directive 98/14/EC of 6 February 1998 adapting to technical progress Council Directive 70/156/ EEC on the approximation of the laws of the Member States relating to the type approval of motor vehicles and their trailers. Official Journal of the European Communities, No L91, 25.3, 1998.

3. Mickūnaitis, V.; Pikūnas, A; Tilindis, V. The system of evaluation of type correspondence for Lithuanian means of road transport. Transport Engineering (Transportas), Vol XVI, No 3, Vilnius: Technika, 2001, p. 105-110 (in Lithuanian).

4. Sendžikas, V, et al. Used cars in Lithuania. The analysis of technical defects. Vilnius: Grafija, 2001. 119 p.

5. Tilindis, V.; Mickūnaitis, V. Fundamentals of the theory of vehicle operation. Vilnius: Technika, 2003. 101 p.

6. Mickūnaitis, V.; Nagurnas, S. The improvement of the technical exploatation of automobiles. Transport, Vol XVII, No 4, Vilnius: Technika, 2002, p. 143-146.

7. Mickūnaitis, V.; Šerènas, R. Influence of vehicle technical defects to traffic safety and protection of the environment. In: Proceedings of 4-th International Conference TRANSBALTICA-03, held on April 10-11, 2003, Vilnius: Technika, 2003, p. 272-275 (in Lithuanian). 